\title{
Effect of Inspiratory Resistive Loading on Costal and Crural Diaphragm Electromyograms in Piglets
}

\author{
J. F. WATCHKO, D. E. MAYOCK, T. A. STANDAERT, AND D. E. WOODRUM \\ Department of Pediatrics, Division of Neonatal and Respiratory Diseases, University of Washington, \\ Seattle, Washington 98195
}

\begin{abstract}
We examined the effect of inspiratory resistive loaded breathing (IRL) on the electromyographic (EMG) activity of the costal and crural diaphragm in nine anesthetized spontaneously breathing piglets (age 10-23 days, weight $2.8-4.4 \mathrm{~kg}$ ). Bipolar wire electrodes were inserted into the anterior paratendinous costal diaphragm and the midportion of the crural diaphragm. EMG activity was quantified in arbitrary units (au) of peak moving time average while the animals breathed $50 \% \mathrm{O}_{2} / 50 \% \mathrm{~N}_{2}$ (baseline) and during $30 \mathrm{~min}$ of IRL. Thirty min of IRL increased the peak moving time average of both parts of the diaphragm, with the increase in the crural EMG activity (from baseline: $22 \pm 2$ to 30 min of IRL: $76 \pm 22$ au) exceeding that of costal (from baseline: $23 \pm 2$ to 30 min of IRL: 50 \pm 24 au), $p<0.05$. These results 1) suggest that the inspiratory EMG activity of the diaphragm can be differentially distributed between its costal and crural components and 2) document that crural inspiratory EMG activity undergoes greater augmentation under the condition of IRL than does the costal activity in piglets. (Pediatr Res 21: 25-28, 1987)
\end{abstract}

\section{Abbreviations}

EMG, electromyographic

au, arbitrary units

IRL, inspiratory resistive loaded breathing

Experimental evidence from adult animal studies suggests that the costal and crural portions of the diaphragm may be two separate muscles (1-4). Specifically, differences in the mechanical actions (1), fiber composition (2), embryologic development (3), and segmental innervation (4) of the costal and crural segments have been documented. Furthermore, investigators have recently reported differential costal and crural diaphragm EMG activity during periods of heightened respiratory drive $(5,6)$, suggesting that the neural control of the two diaphragmatic segments may be different.

The effect of loaded breathing on costal and crural EMG activity has not been evaluated within a neonatal context. Developmental changes in 1) the diaphragmatic muscle $(7), 2)$ the mechanical properties of the respiratory system (8), and 3 ) the chemosensory and mechanoreflex systems (9-11) of mammals

Received May 7. 1986; accepted August 8, 1986.

Address correspondence and reprint requests to Jon F. Watchko, M.D. Division of Neonatal and Respiratory Diseases. Department of Pediatrics RD-20, University of Washington. Seattle. WA 98195.

Supported in part by Public Health Service Grants NIH HL19187 and MCH 000955 . are known to exist. Thus, one cannot assume that the EMG activity of the costal and crural segments of the developing diaphragm, in response to heightened respiratory drive, are similar to those of the adult. We therefore examined the effect of inspiratory resistive loaded breathing on the EMG activity of the costal and crural diaphragm in the piglet. We hypothesized that the inspiratory EMG activity of the diaphragm is differentially distributed between its costal and crural components during inspiratory resistive loaded breathing.

\section{METHODS}

Farm bred piglets obtained from the University of Washington vivarium served as our study animal. Experiments were performed on nine piglets of postnatal age 10-23 days (weight 2.8$4.4 \mathrm{~kg}$ ). The animals were anesthetized with an intravenous combination of chloralose $(50 \mathrm{mg} / \mathrm{kg})$ and urethane $(200 \mathrm{mg} /$ $\mathrm{kg}$ ) and studied in the supine position. Subsequent infusions of anesthesia were given if the piglet developed jaw clonus. Only anesthetized piglets with a respiratory rate of 15 to 30 breaths per minute, a $\mathrm{PaO}_{2}$ of greater than 60 torr in room air, and a $\mathrm{PaCO}_{2}$ of less than 50 torr were studied.

The trachea was surgically exposed and cut horizontally. A metal tube $(6.35 \mathrm{~mm}$ OD) was inserted in the distal trachea, secured with suture, and attached to a Hans-Rudolph miniature two-way nonrebreathing valve (no. 2384). A femoral artery and vein were cannulated to monitor blood gases and give anesthesia. A Corning 168 Blood Gas Analyzer (Corning Glass Works, Medfield, MA) was utilized to determine arterial blood gas tensions and $\mathrm{pH}$. Rectal temperature was continuously monitored (YSI Tele-Thermometer 43TA, Yellow-Springs Instrument Co., Yellow-Springs, $\mathrm{OH}$ ) and maintained between $38.5-39.5^{\circ} \mathrm{C}$ (12) by a radiant warmer.

Bipolar wire electrodes were inserted into the anterior paratendinous costal diaphragm and the midportion of the crural diaphragm. Access to the costal diaphragm was obtained by a subcostal extraperitoneal incision. The costal electrode was fashioned from two fine barbed dental broaches (Union Broach Company, Long Island City, NY) embedded in silicon rubber (Dow Corning, Midland, MI) approximately $6 \mathrm{~mm}$ apart. Following costal electrode placement under direct vision, the surgical incision was closed. The crural electromyogram was obtained from two percutaneously placed insulated stainless steel wires (0.01 inch diameter) (13). Postmortem examination in each animal indicated the electrodes were embedded within the crura, usually less than $10 \mathrm{~mm}$ from one another. A third electrode was placed subdermally in the right thigh to provide an electrical ground. Electrode placement was unilateral and on the right side in all the study animals. The animal preparation is schematically illustrated in Figure 1.

Costal and crural EMG signals were recorded differentially to 


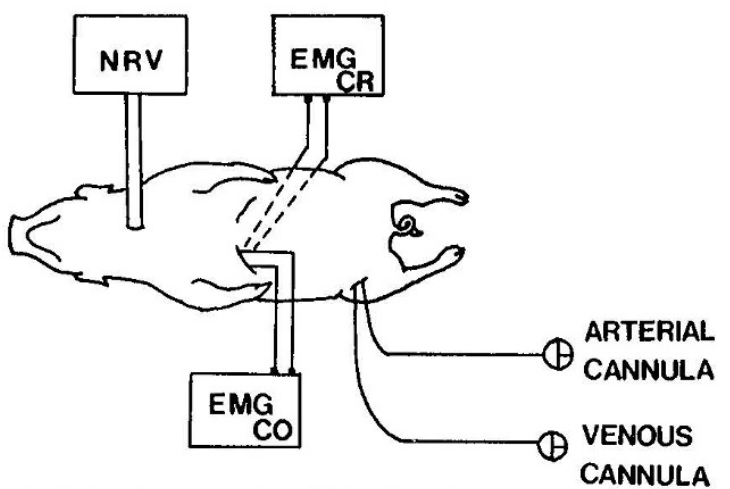

Fig. 1. Animal preparation. Piglet breathes spontaneously through a nonrebreathing valve $(N R V)$. Recording electrodes are attached to the costal $\left(E M G_{C O}\right)$ and crural $\left(E M G_{C R}\right)$ diaphragm. Femoral artery and venous catheters are in place.

ground and amplified 1 to $10 \times 10^{3}$ times on a Grass Preamplifier (P511J) prior to recording on an FM tape recorder (Honeywell $5600 \mathrm{C})$. The EMG signal was processed further utilizing a Service Associates 414 analog processor where it was filtered to allow passage of frequencies between 30 and $3000 \mathrm{~Hz}$. The EMG was full-wave rectified and integrated through a simple $\mathrm{R}-\mathrm{C}$ filter $(\tau=100 \mathrm{~ms})$ to obtain moving average (14). The EMG and processed signals were displayed on a Tektronix $5111 \mathrm{~A}$ storage oscilloscope and a Gould four-channel chart recorder (Brush 440).

Our experimental protocol included the measurement of 1) costal and crural diaphragmatic inspiratory electrical activity quantified in au of peak moving time average and 2) arterial blood gases while the animals breathed $50 \% \mathrm{O} 2 / 50 \% \mathrm{~N} 2$ during baseline and during $30 \mathrm{~min}$ of IRL. The numeric values of all EMG activities were determined from the average of six to 10 breaths during the baseline period and at the 5, 10, 15, and 30 min points of IRL. The inspiratory resistor utilized in this study was a stainless steel tube placed in line with the inspiratory port of the nonrebreathing valve. The resistance of the tube was 0.65 $\mathrm{cm} \mathrm{H}_{2} \mathrm{O} / \mathrm{ml} / \mathrm{min}$ measured at $600 \mathrm{ml} / \mathrm{min}$. Data for all piglets are reported as a mean \pm SD of the mean. The Mann-Whitney two sample rank procedure for nonparametric data (Minitab Release, Penn State University, 1980) was used for analysis of the EMG data, and the paired $t$ test (Minitab Release, Penn State University, 1980) was used to analyze the blood gas data. The criteria for statistical significance was $p<0.05$.

\section{RESULTS}

Arterial blood gas determinations were obtained during the baseline period and after $30 \mathrm{~min}$ of IRL. A significant decline in arterial pH (baseline: $7.36 \pm 0.03$; IRL: $7.17 \pm 0.07, p<0.05$ ) and rise in arterial carbon dioxide levels (baseline: $45 \pm 4$ torr; IRL $78 \pm 14$ torr, $p<0.05$ ) were documented at $30 \mathrm{~min}$ of IRL. The arterial oxygen levels also declined as predicted by the alveolar air equation in the context of significant carbon dioxide retention (baseline: $199 \pm 20$ torr; IRL: $135 \pm 20$ torr, $p<0.05$ ). Nevertheless, the arterial oxygen levels were always greater than 100 torr. Thus, the piglets developed a significant degree of respiratory acidosis and remained hyperoxic during IRL.

The effect of IRL on peak moving time average costal and crural diaphragm electrical activity is shown for one piglet in Figure 2 . In this piglet, the crural diaphragm increased its activity to a greater extent than did the costal diaphragm. Table 1 documents the data average for all nine piglets. Thirty min of IRL increased the peak moving time average of the costal (baseline: $23 \pm 2 \mathrm{au}, 30 \mathrm{~min}$ IRL: $50 \pm 24 \mathrm{au}$ ) and crural (baseline: $22 \pm 2$ au, 30 min IRL: $76 \pm 22$ au) diaphragm electrical activity compared to their respective baseline values $(p<0.05)$. The increase in the crural EMG activity exceeded that of the costal
EMG activity during IRL and was statistically significant $(p<$ $0.05)$.

The time course of peak moving time average EMG activities of costal and crural diaphragm during inspiratory resistive loaded breathing is seen in Figure 3. At the 5, 10, 15, and 30 min points of inspiratory resistive loaded breathing, the increases in activity of the crural diaphragm were greater than those of the costal diaphragm $(p<0.05)$. A progressive increase in both crural and costal EMG activity was seen throughout the period of loading. Arterial $\mathrm{PaCO}_{2}$ values were significantly elevated at the $30 \mathrm{~min}$ point of inspiratory resistive loaded breathing compared to baseline.

\section{DISCUSSION}

The data reported herein represent the first analysis of costal and crural diaphragmatic EMG activities within a neonatal context during a period of heightened respiratory drive. Our data document that crural inspiratory EMG activity undergoes greater augmentation under the condition of inspiratory resistive loaded breathing than does costal activity in piglets.

Critique. The diaphragmatic electromyogram has been used as an index of neural output of the respiratory centers during periods of heightened respiratory drive (14). The reliability of this index is dependent on 1) the position of the recording electrode relative to the diaphragm $(15), 2)$ the electrical conductivity of the immediate environment of the costal diaphragm (16), and 3) the length-tension state of the diaphragm (17).

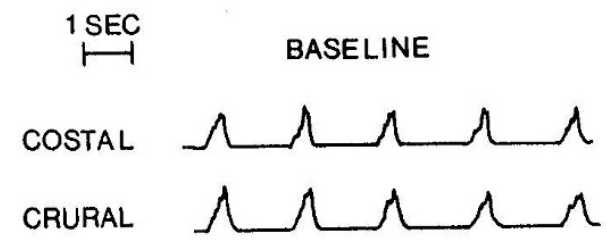

LOADED BREATHING

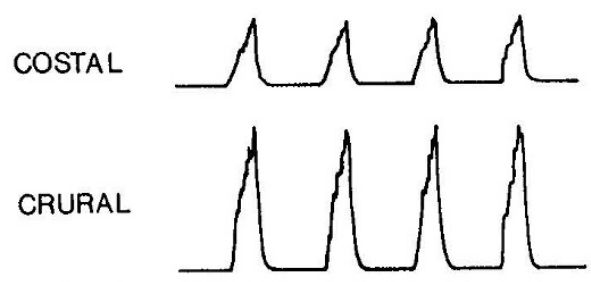

Fig. 2. Example of moving time average electromyograms recorded from the costal and crural diaphragm in one piglet during the baseline condition (baseline) and after $30 \mathrm{~min}$ of inspiratory resistive loaded breathing (loaded breathing). The augmentation in crural diaphragmatic electrical activity is greater than that of costal activity at $30 \mathrm{~min}$ of inspiratory resistive loaded breathing in this piglet. Time scale calibration is $1 \mathrm{~s}$.

Table 1. Effects of IRL on costal and crural diaphragmatic EMG activity

\begin{tabular}{|c|c|c|c|}
\hline & $\begin{array}{l}\text { Baseline } \\
\text { (au) }\end{array}$ & $\begin{array}{c}30 \min \text { IRL } \\
(\mathrm{au})\end{array}$ & $\begin{array}{c}\text { Increase in } \\
\text { activity } \\
(\% \\
\text { control) }\end{array}$ \\
\hline Costal diaphragm & $23 \pm 2$ & $50 \pm 24^{*}$ & $231 \pm 74$ \\
\hline Crural diaphragm & $22 \pm 2$ & $76 \pm 22 *$ & $341 \pm 92 \dagger$ \\
\hline
\end{tabular}

${ }^{*} p<0.05$ compared to baseline values.

$\dagger p<0.05$ compared to costal values. 


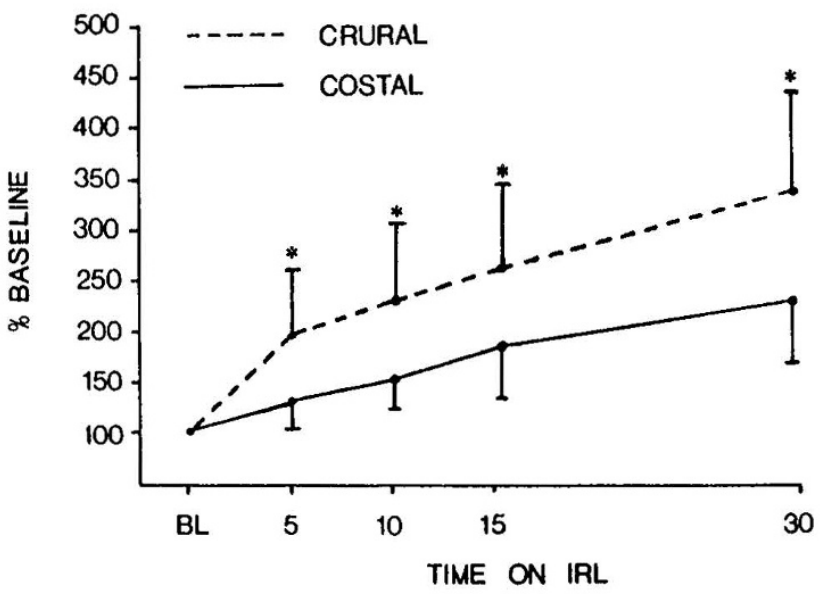

Fig. 3. The time course of peak moving time average EMG activities of costal and crural diaphragm during IRL. Peak moving time average EMG activity is expressed as a percent of baseline value. Solid line, costal EMG; dashed line, crural EMG. Bars are SD. ${ }^{*} p<0.05$.

In order to avoid changes in EMG activity secondary to variations in the position of the recording electrode relative to the diaphragm (e.g. esophageal recording techniques), we utilized EMG signals recorded from electrodes anchored in the diaphragm itself (15).

Furthermore, in order to avoid changes in EMG activity secondary to alterations in the electrical conductivity of the immediate environment of the costal diaphragm electrode, we placed this electrode in a paratendinous position (15). By doing so, changes in the conductivity of the immediate environment of the costal diaphragm recording electrode that may have occurred secondary to alterations in lung volume and/or chest wall configuration during IRL were minimized $(15,16)$. If, however, the paratendinous costal diaphragm recording electrode came transiently in contact with the rib cage, augmentation of the costal EMG signal would have occurred, minimizing the observed costal/crural differences in peak moving time average (15). We do not believe this to be a concern in our preparation.

Finally, Kim et al. (17) have recently reported that diaphragmatic EMG signals recorded during isometric in vitro contractions elicited in response to "supramaximal" phrenic nerve stimulation are a function of the diaphragm's length. The relevance of this observation to EMG activity recorded in vivo during nonisometric contractions has yet to be determined. Furthermore, these investigators noted that during more physiologic submaximal phrenic nerve stimulations, changes in muscle length had little effect on EMG activity. Corroborating this latter observation are other reports documenting that lung volume changes have little effect on directly recorded diaphragmatic EMG signals in vivo $(15,18)$. Thus, we believe that our diaphragmatic EMG recordings are an acceptable index of central neural respiratory output.

Our study was performed under anesthesia, a condition that may alter the response of the animal to resistive loaded breathing (19). We have observed, however, that the response to inspiratory resistive loading in anesthetized piglets (20) is qualitatively similar to that reported in awake sheep (19) suggesting that the effects of anesthesia were minimal. Nevertheless, our data should be interpreted with the knowledge that anesthesia was used.

Effects of inspiratory resistive loaded breathing. The present study documents that the crural diaphragm electrical activity is augmented more than its costal counterpart during inspiratory resistive loaded breathing. Qualitatively similar results have been noted in adult dogs during hypercapnic exposure and bronchoconstriction (5) and in adult cats during hypercapnic exposure and postural changes (6). Although we cannot assess how much of the costal and crural EMG activity changes are due to the resistive load as opposed to the presence of respiratory acidosis, it would appear that the differential augmentation between diaphragm segments cannot be explained on the basis of hypercapnia in piglets. Specifically, we have examined the level of costal and crural diaphragm EMG activities during hypercapnic drive ( $10 \% \mathrm{CO}_{2}$ breathing: $\mathrm{PaCO}_{2}=77 \pm 5$ torr, $n=5$ ). Our preliminary results document no significant differences between costal and crural EMG activity augmentation during $\mathrm{CO}_{2}$ breathing. Others have reported similar results in lambs (21). These data suggest that hypercapnia per se does not lead to differential augmentation of the costal and crural diaphragm segments within a neonatal context.

The mechanisms that may account for the greater augmentation in crural when compared to costal activity during periods of heightened respiratory drive are not known. However, investigators have documented that the crural diaphragm has greater proprioceptive innervation than does the costal diaphragm (22). This finding has led to speculation that information from these receptors preferentially facilitate neural drive to the crural diaphragm during loading (6). Such facilitation has been hypothesized to occur with intercostal muscles laden with proprioceptive innervation in response to changes in posture (23). Others have speculated that the costal and crural segments have separate central pattern generators, and that the differential response to loaded breathing and/or hypercapnia is due to the differential response of these generators $(6,24)$. Finally, vagal stretch receptor afferent input has been shown to exert a quantitatively greater inhibitory effect on inspiratory EMG activity (moving time average) to the costal than crural diaphragm and may account, in part, for the observed differential response to loaded breathing (25).

In summary, the data collected in this investigation document that inspiratory EMG activity of the diaphragm can be differentially distributed between its costal and crural components during inspiratory resistive loaded breathing. Our data are consistent with the observations of other investigators $(1,5,6)$ and support the concept that the neural control of the two segments of the diaphragm is different. The functional importance and clinical relevance of these data remain uncertain. Nevertheless, one could speculate, given the separate mechanical effects the costal and crural diaphragm have on the rib cage (1), that separate modulation of costal and crural activity within the central nervous system is another mechanism by which ventilation is controlled.

\section{REFERENCES}

1. DeTroyer A, Sampson M, Sigrist S, Macklem PT 1981 The diaphragm: two muscles. Science 212:237-238

2. Riley DA, Berger AJ 1979 A regional histochemical and electromyographic analysis of the cat respiratory diaphragm. Exp Neurol 66:636-649

3. Langman J 1975 Medical Embryology. Williams \& Wilkins, Baltimore, pp 305-307

4. Sant'Ambrogio G, Frazier DT, Wilson MF, Agostoni E 1963 Motor innervation and pattern of activity of cat diaphragm. J Appl Physiol 18:43-46

5. Van Lunteren E, Haxhill MA, Chandler Deal E, Perkins D, Cherniak NS 1984 Effects of $\mathrm{CO}_{2}$ and bronchoconstriction on costal and crural diaphragm electromyograms. J Appl Physiol 57:1347-1353

6. Van Lunteren E, Haxhiu MS, Cherniak NS, Goldman MD 1985 Differential costal and crural diaphragm compensation for posture changes. J Appl Physiol 58:1895-1900

7. Maxwell LC, McCarter JM, Kuehl TJ, Robothan JL 1983 Development of histochemical and functional properties of baboon respiratory muscles. $\mathrm{J}$ Appl Physiol 54:551-561

8. Grunstein MM, Tanaha DT 1985 Ontogeny of respiratory control and pulmonary mechanics in newborn rabbits. J Appl Physiol 59:1477-1486

9. Adler SM, Thach BT, Frantz I 1976 Maturational changes of effective elastance in the first 10 days of life. J Appl Physiol 40:539-542

10. Rigatto H, Brady JP, de la Torre Verduzco R 1975 Chemoreceptor reflexes in preterm infants: I. The effect of gestational and postnatal age on the ventilatory response to inhalation of $100 \%$ and $15 \%$ oxygen. Pediatrics 55:604613

11. Rigatto H, Brady JP, de la Torre Verduzco R 1975 Chemoreceptor reflexes in preterm infants: II. The effect of gestational and postnatal age on the ventilatory response to inhaled carbon dioxide. Pediatrics 55:614-621

12. Mount LE, Ingram DL 1971 Physiology. In: The Pig as a Laboratory Animal. Academic Press, New York, pp 65-78 
13. Trelease RB, Sieck GC, Harper RM 1982 A new technique for acute and chronic recording of crural diaphragm EMG in cats. Electroencephalogr Clin Neurophysiol 53:459-462

14. Lopata M. Evanich MJ. Lourenco RV 1977 Quantification of diaphragmatic EMG response to $\mathrm{CO} 2$ rebreathing in humans. J Appl Physiol 43:262-270

15. Grassino AE. Whitelaw WA, Milic-Emili J 1976 Influence of lung volume and electrode position on electromyography of the diaphragm. J Appl Physiol 40:97!-975

16. Banzett R. Bruce E. Goldman M. Mead J 1977 Artifactual changes in diaphragm EMG amplitude caused by mechanical interventions to breathing. Physiologist 20:5(abstr)

17. Kim MJ. Druz WS, Sharp JT 1985 Effect of muscle length on electromyogram in a canine diaphragmatic strip preparation. J Appl Physiol 58:1602-1607

18. Kim MJ. Druz WS. Danon J. Machnach W, Sharp JT 1978 Effects of lung volume and electrode position on the esophageal diaphragmatic EMG. J Appl Physiol 45:392-398

19. Sadoul N, Bazzy AR, Akabas SR, Haddad GG 1985 Ventilatory response to fatiguing and nonfatiguing resistive loads in awake sheep. J Appl Physiol 59:969-978

20. Badura RJ, Watchko JF, LaFramboise WA, Woodrum DE 1984 Diaphragmatic fatigue in the neonatal piglet. Pediatr Res 18:385A

21. Cooke IRC, Soust M, Wilson FE, Berger PJ 1986 Activation of respiratory muscles in the lamb in response to chemical drive. Proceedings of the International Union of Physiological Sciences 16:49A

22. Duron B, Jung-Caillol MC, Marlot D 1978 Myelinated nerve fiber supply and muscle spindles in respiratory muscles of cat: quantitative study. Anat Embryol 152:171-192

23. Corda M, von Euler C, Lennerstrand G 1966 Reflex and cerebellar influences on $\alpha$ and on 'rhythmic' and 'tonic' activity in the intercostal muscle. J Physiol (Lond) 184:898-923

24. Richardson CA, Mitchell RA 1982 Power spectral analysis of inspiratory nerve activity in the decerebrate cat. Brain Res 223:317-336

25. Chen HI, Dabral M, Kelsen SG 1985 Effects of vagal afferent input and hypercapnia on costal and crural EMG. Fed Proc 44:835A 